\title{
THE APPLICATION OF GEOSTATISTICAL METHODS TO THE HYDROLOGICAL INTERPRETATION OF GEOELECTRICAL SOUNDINGS
}

\author{
E. Brückl ${ }^{*}$, R. Dutter ${ }^{*}$, A. Schiller ${ }^{*}$ D. Bechtold ${ }^{* *}$, J. Dölzlmüller ${ }^{+}$, M. Lumassegger ${ }^{*}$ \\ *) Vienna University of Technology, Gußhausstr. 27-29, A-1040 Vienna, Austria \\ **) Büro für.Geologie und Hydrologie, A-5164 Seeham, Austria \\ +) Tauernplan Geophysik GmbH, Rainerstr. 29, A-5021 Salzburg, Austria \\ $\left.{ }^{+}\right)$ILF-Consulting Engineers, Framsweg 16, A-6020 Innsbruck, Austria
}

\section{INTRODUCTION}

During the planning of a new railway line through Tirol, Austria comprehensive multidisciplinary hydrological studies were carried out. The goal of these activities was the establishment of hydrological models to simulate the potential influence of the planned railway line on the existing groundwater regime. One part of these investigations were conventional geoelectrical soundings. In this paper we describe the application of geostatistical methods to the hydrological interpretation of the geoelectrical data. and we analyze the impact of the geoelectrical information on the final hydrological model.

\section{SITUATION}

The general hydrogeological situation is characterized by an unconfined groundwater table less than $10 \mathrm{~m}$ below ground surface, permeable layers which are some $10 \mathrm{~m}$ thick and a rather gradual transition to impermeable layers. About 100 drillholes with a mutual distance of about $300 \mathrm{~m}$ cover four investigation areas. Geological and geophysical logs and data from soil-mechanical and hydrological tests are available, however, not all drillholes reached the impermeable layers. About 100 Schlumberger soundings were carried out at locations between the drillholes. These soundings were inverted by standard procedures yielding a "smooth model" and a "layer model" for each sounding.

\section{STRUCTURAL INTERPRETATION AND MODELLING}

An inspection of the results from drillholes and the geoelectrical models showed, that the "smooth model" better describes the geological situation than the "layer model". A decay 
of the resistivity below 80 or $120 \mathrm{Ohm}$ m was correlated with the top of the more or less impermeable layers.

The main task of the structural interpretation was the establishment of models of the top of the impermeable layers using both drillhole and geoelectrical information. There are different classes of information which are illustrated in Figure1 and described in the following:

A: drillholes reaching the impermeable strata (about $50 \%$ of all drillholes)

B: drillholes reaching the transition zone; the top of the impermeable strata may be estimated by subtracting the mean thickness of the transition zone from top of the transition zone or taking the drilling depth if this level is deeper

$\mathrm{C}$ : drillholes ending within the permeable strata; an upper bound of the top of the impermeable strata may be estimated by subtracting the mean thickness of the transition zone from the drilling depth.

D: geoelectrical soundings with a decay below 80 or $120 \mathrm{Ohm} \mathrm{m} \mathrm{(>90 \% )}$

E: geoelectrical soundings with no indication of the impermeable strata.

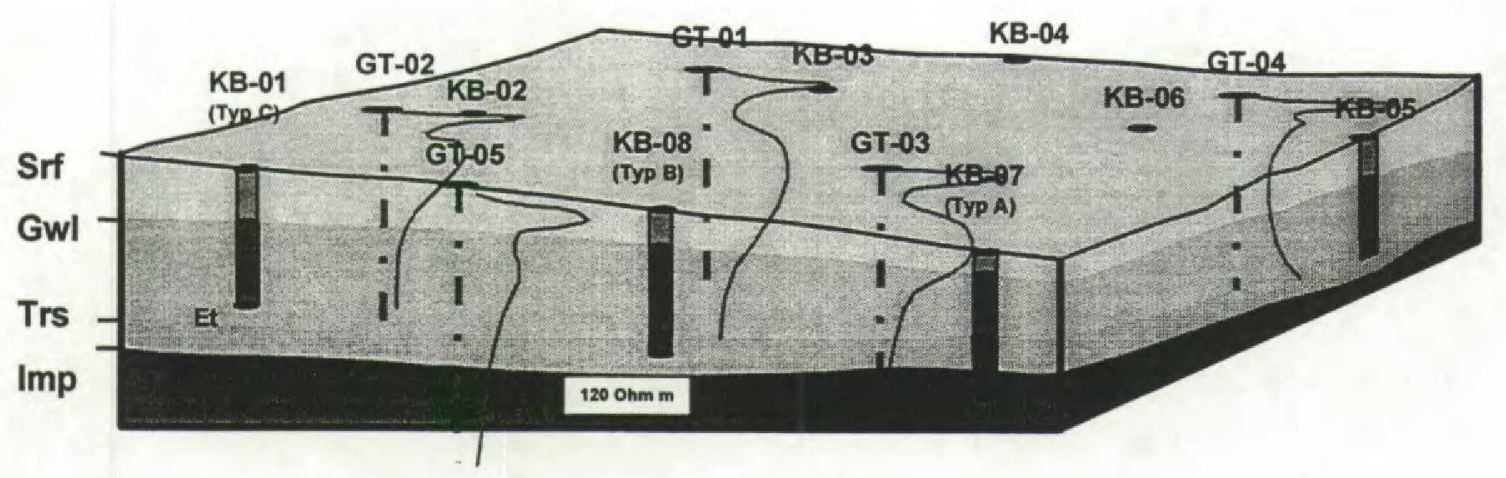

A

B

C

D

$\mathbf{E}$
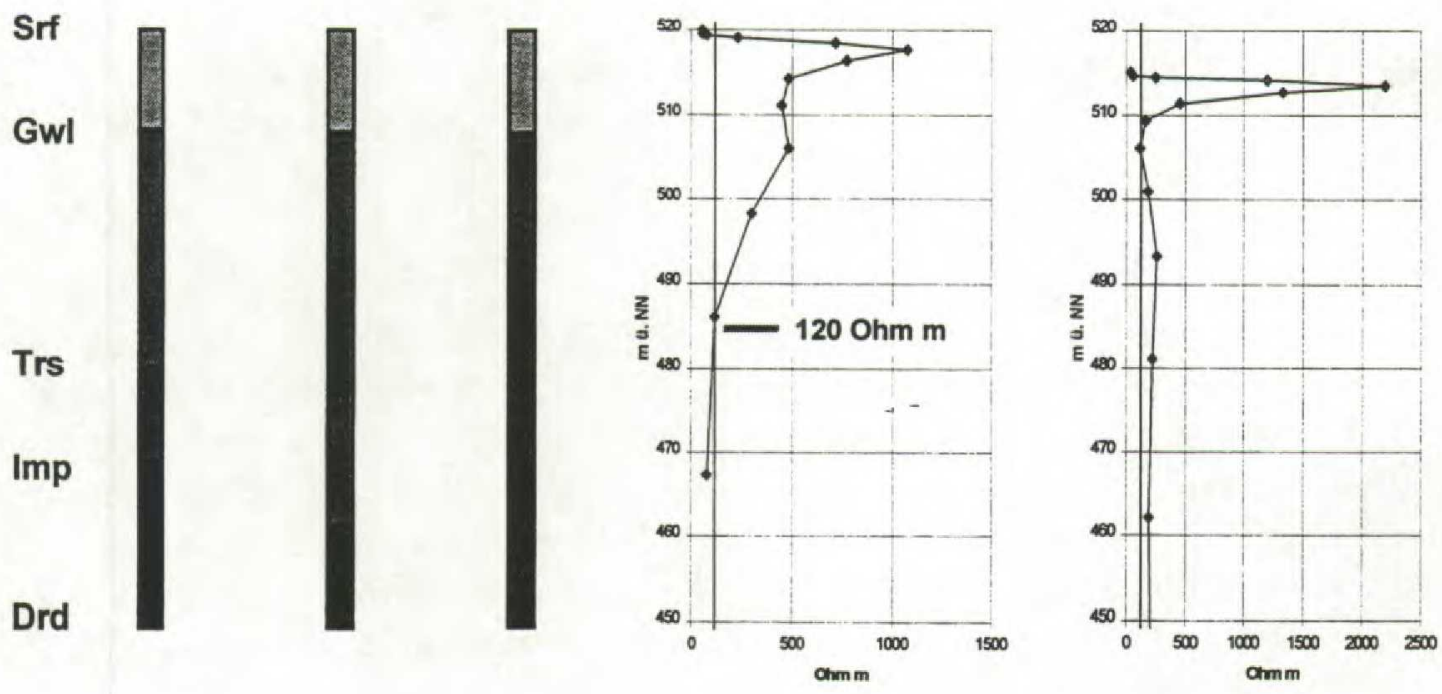

Figure 1: Classes of information available for the construction of a hydrological model Legend: $\quad$ Srf surface

Gwl groundwater level

Trs top of transition zone

Drd drilling depth

Imp top of impermeable layers 
The first step of the structural interpretation is the estimate of a calibration factor for the geoelectrical depth information in each testing area. Due to the three classes of information from drillholes and the fact that the drillholes are not at the locations of the geoelectrical soundings, we chose the following procedure:

a) Kriging the geoelectrically determined values of the top of the impermeable strata ZI_g (information class D) to the locations of the drillholes XY d.

b) Calculation of individual calibration factors $k_{-} d$ at $X \bar{Y}_{-} d$.

c) Maximization of the arithmetic mean of $k \bar{d}$ by excluding data values from the classes $\mathrm{C}$ and eventually $\mathrm{B}$.

d) Kriging the remaining $k_{-} d$ from the locations $X Y \_d$ to the locations of the geoelectrical soundings $X Y$ g yielding $\mathbf{k} \_g$, or determining the spatially weighted mean $\mathbf{k}$.

e) Calculation of calibrated geoelectrical depth information (class F).

The next and final step in structural interpretation and modelling is the interpolation of the top of the impermeable strata utilizing information from the classes $A, B, C$ and $F$. The following procedure was applied:

1) Define the kriging support by the information of the classes $A$ and $F$.

2) Perform kriging to the locations of the drillholes with information of classes $B$ and $\mathrm{C}$ (target) yielding $\mathrm{Z}$ i.

3) Test: if $\left(Z_{-} i<\right.$ estimated from information of class $\left.B / C\right)$ goto 5

4) Shift the information of class $B / C$ with the minimum value of $\left(Z_{-} i\right.$ - estimated from information of class $B / C$ ) from the kriging target to the kriging support and goto 2 .

5) Perform kriging at a grid.

By the application of the calibration and interpolation procedures described above we constructed models of the top of the impermeable strata (Figure 2) consistent with geological considerations and suitable for FE-modelling. The improvement of the variogram may be evaluated as a statistical measure of the performance of the procedures.
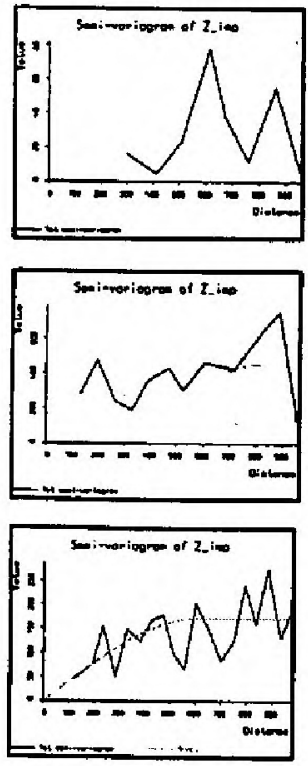

A

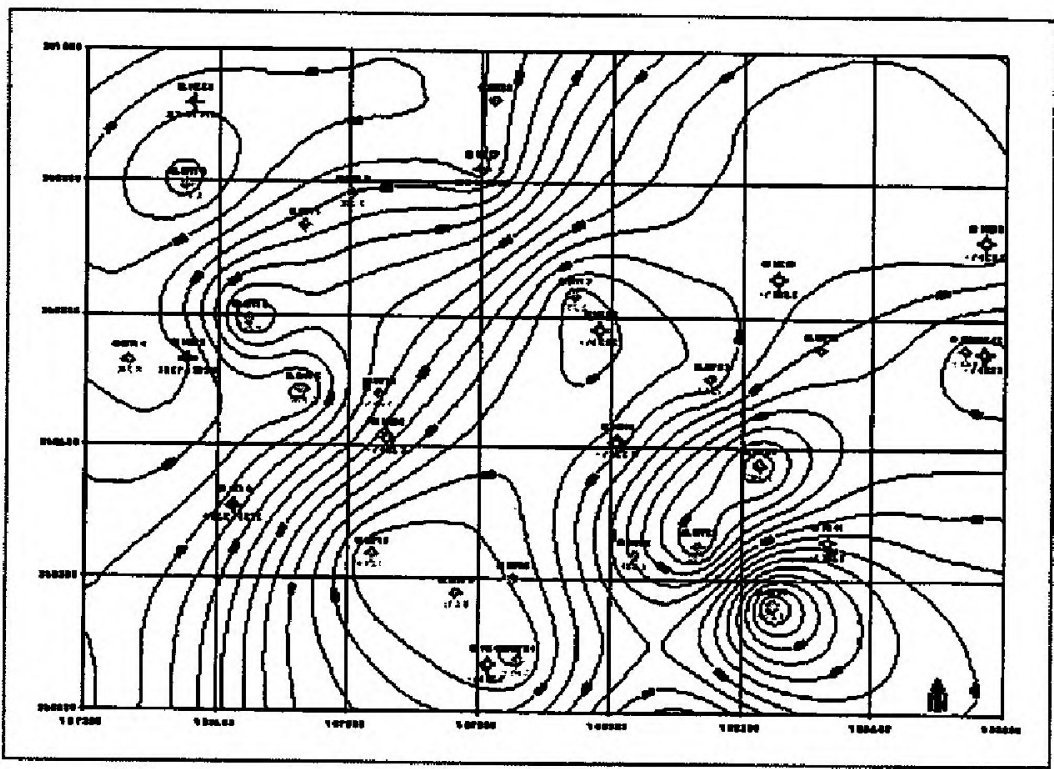

Figure 2: Semi-variograms and structural map of the top of the impermeable layers

A/B semi-variograms of borehole/geoelectrical data

C combined semi-variogram of borehole and calibrated geoelectrical data 
A statistically optimal interpolation (kriging) of the resistivity (permeable and impermeable layers) and the formation factor (only permeable layers) to the drillhole locations was done and the following correlations were investigated:

resistivity of permeable layers versus resistivity of ground water resistivity/formation factor of permeable layers versus clay content resistivity/formation factor of permeable layers versus permeability (labor/field tests) resistivity of impermeable layers versus clay content resistivity of impermeable layers versus permeability (labor/field tests).

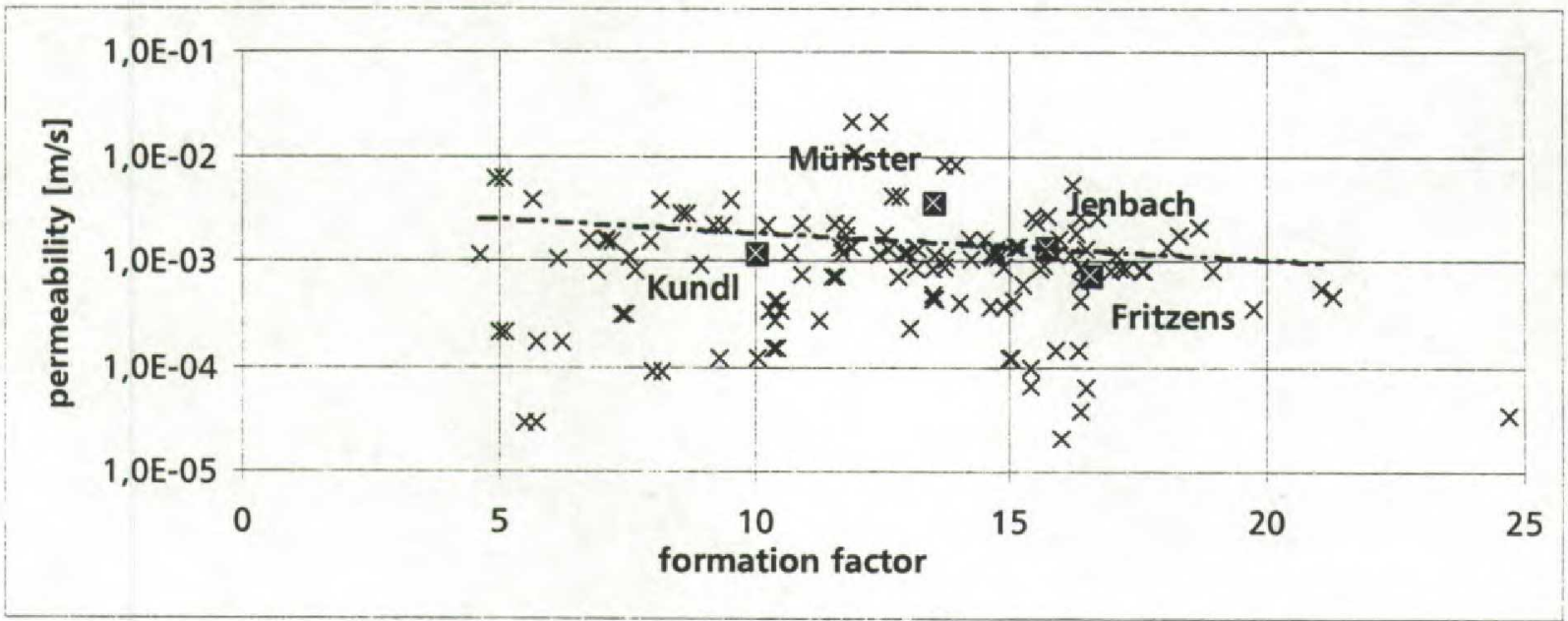

Figure 3: Permeability (field tests) versus formation factor of the permeable layers

As an example Figure 3 shows the cross plot of the permeability of the permeable layers versus the formation factor. We may see that there is almost no correlation. By the known errors of spatial interpolation it is possible to decide, if this poor correlation is due to the corse spatial sampling or if the two parameters do not closer correlate within the geological conditions under consideration. These investigations are still in progress.

\section{CONCLUSIONS}

Geostatistical methods were successfully used in the joint hydrological interpretation of geoelectrical soundings and the geological information from drillholes. The advantages may be summarized by the following items:

applicability to a very arbitrary layout of drillholes and geoelectrical soundings

supply of a reasonable structural model for the hydrological modelling

range of the variability of model parameters used by sensitivity studies

judgement of the significance of correlations between geoelectrical and hydrological parameters

judgement of the quality and sufficiency of spatial sampling.

\section{ACKNOWLEDGMENT}

We thank Brenner Eisenbahn GmbH, Austria, for the permission to publish these results. 